Valera, F., and R. Václav. 2021. Residency patterns and apparent survival in a cavity-nesting bird: population consequences of nest-box supplementation revealed by a long-term study. Avian Conservation and Ecology 16(2):8. https://doi.org/10.5751/ACE-01928-160208

Copyright (C) 2021 by the author(s). Published here under license by the Resilience Alliance.

Research Paper

\title{
Residency patterns and apparent survival in a cavity-nesting bird: population consequences of nest-box supplementation revealed by a long-term study
}

\author{
Francisco Valera ${ }^{1}$ and Radovan Václav ${ }^{2}$ \\ ${ }^{1}$ Departamento de Ecología Funcional y Evolutiva, Estación Experimental de Zonas Áridas (EEZA-CSIC), Almería, Spain, \\ ${ }^{2}$ Institute of Zoology, Slovak Academy of Sciences, Bratislava, Slovakia.
}

ABSTRACT. Phenotypic plasticity may help organisms persist in modified habitats. Yet, its adaptive value is frequently ignored because fitness consequences are not explored at the required time scale. Taking advantage of a 16-yr nest-box supplementation program, we explored effects of nest type and two social-ecological indices (breeding cluster size and distances between clusters) on adult and offspring survival of a non-excavator cavity-nesting bird species, the European roller (Coracias garrulus), a species of conservation concern. We also investigated site and habitat fidelity associated with different nest types. Apparent survival of rollers was mainly explained by age and sex. Social-ecological factors were more important than cavity type in apparent survival. Increases in apparent survival with decreasing distance to neighboring clusters were comparable for adult males and females but were stronger for juvenile males than for juvenile females. Nest type influenced residency patterns, so that males breeding in nest-boxes were more likely to be recaptured in subsequent years at the study site and in the same nest type compared with males associated with natural and semi-natural nest types. Whereas phenotypic plasticity in nest selection might favor rapid colonization of a novel nest type, widespread use of nestboxes can decrease, through their effects on site and habitat fidelity, a species' responsiveness to environmental changes. We suggest that nest-box schemes should be applied to promote higher connectiveness of breeding populations and that nest-box programs may influence population dynamics and habitat selection criteria via their effect on social information and natal habitat preference induction.

\section{Modèles de résidence et survie apparente d'un oiseau nichant dans les cavités : les conséquences des nichoirs supplémentaires sur la population révélées par une étude de longue durée}

RÉSUMÉ. La plasticité phénotypique pourrait aider les organismes à persister dans des habitats modifiés. Pourtant, sa valeur adaptative est fréquemment ignorée, car les conséquences en termes d'adéquation ne sont pas explorées sur l'échelle de temps requise. En nous appuyant sur un programme d'installation de nichoirs supplémentaires sur une période de 16 ans, nous avons examiné les effets des types de nichoirs et deux index socio-écologiques (taille des pôles de reproduction et distance entre les pôles) sur la survie des adultes et des petits d'une espèce d'oiseaux non-excavateurs nichant dans les cavités, le rollier d'Europe (Coracias garrulus), espèce dont la conservation est préoccupante. Nous avons aussi enquêté sur le site et la fidélité à l'habitat associés à différents types de nid. La survie apparente des rolliers s'expliquait principalement par l'âge et le sexe. Les facteurs socio-écologiques étaient plus importants que le type de cavité pour la survie apparente. L'augmentation de la survie apparente liée à la réduction de la distance par rapport aux pôles voisins était comparable chez les mâles et les femelles adultes, mais plus élevée chez les jeunes mâles que chez les jeunes femelles. Le type de nid influençait les modèles de résidence : ainsi, les mâles qui se reproduisaient dans des nichoirs étaient plus susceptibles d'être à nouveau capturés lors des années suivantes sur le site de l'étude et dans le même type de nid, par rapport aux mâles associés à des types de nid naturels et semi-naturels. Si la plasticité phénotypique dans la sélection du nid pourrait favoriser la colonisation rapide d'un nouveau type de nid, l'utilisation étendue des nichoirs risquerait de diminuer la réactivité d'une espèce aux changements d'environnement, de par ses effets sur la fidélité à un site et un habitat. Nous suggérons d'appliquer des programmes de nichoirs pour promouvoir une connectivité supérieure des populations reproductrices : en effet, les nichoirs pourraient influencer la dynamique des populations et les critères de sélection de l'habitat, de par leur effet sur les informations sociales et l'induction de préférences en termes d'habitat natal.

Key Words: apparent survival; fidelity; nest-box; nest type; population fragmentation

\section{INTRODUCTION}

Growth and spread of human populations inevitably resulted in increasing habitat fragmentation and degradation, thus leading to landscape simplification and decreasing habitat suitability for many organisms (e.g., Geri et al. 2010). These landscape-scale processes as a rule affect the availability and quality of basic resources such as food (Rey 2011) or reproductive sites (Cockle et al. 2010) and bring about changes in various aspects of avian biology such as community structure and individual life-history strategies, survival, breeding performance, or behavior (Richmond et al. 2011, Villegas Vallejos et al. 2016, Reynolds et al. 2019). Importantly, all organisms show a certain ability to respond to changing environmental conditions through

Correspondent author: Francisco Valera, Departamento de Ecología Funcional y Evolutiva, Estación Experimental de Zonas Áridas (EEZA-CSIC), Ctra. de Sacramento s/n, La Cañada de San Urbano, Almería, E-04120, Spain, pvalera@eeza.csic.es 
phenotypic plasticity (see Fox et al. 2019). In fact, rapidly changing environmental conditions may exert selection on plasticity itself (Diamond et al. 2017), thus enabling organisms to colonize, survive, and reproduce in increasingly modified habitats.

Birds invest considerable time and energy in selection of suitable nest sites, and nest characteristics are critical aspects of avian reproduction (Martin and Li 1992, Deeming 2002, Deeming and Mainwaring 2015). Nest-site selection is thought to be evolutionarily conservative because of shared ancestry (Collias and Collias 1984) or because the main selective forces, such as predation, may exert strong stabilizing selection (Martin 1993, Clark and Shutler 1999). Yet, some degree of adaptive phenotypic plasticity in nest-site choice has been reported in birds (e.g., Peluc et al. 2008, Barrientos et al. 2009). Even though plasticity may be of great importance to birds breeding in rapidly changing landscapes (e.g., Reynolds et al. 2019), evaluation of the adaptive value of plasticity in nest-site choice requires knowledge of fitness consequences of choosing different types of nest sites (Forstmeier and Weiss 2004).

Though certain short-term aspects of the effect of nest-site characteristics on demographic parameters have been well studied, e.g., influence of nest-site type on breeding performance (Bolton et al. 2004, Sutherland et al. 2014, Slevin et al. 2018), long-term effects are typically overlooked. For instance, little is known about the effect of nest-site type on individual survival or site fidelity (but see Bellrose et al. 1964, Kirmse 2001, White et al. 2002, Brown and Collopy 2013 for comparisons between natural and artificial nests). Understanding the consequences of nest-site type choice in demographic processes is particularly important because of the widespread use of artificial nest types, e.g., nest-boxes, as a key conservation strategy for cavity-nesting organisms as well as the increasing use of artificial nesting substrates, e.g., houses, factory plants, road or power line infrastructures, etc., in urbanized environments (Mainwaring 2015, Reynolds et al. 2019).

Nest-box schemes have proved useful to produce population increases of threatened species (e.g., Beyer and Goldingay 2006, Rodríguez et al. 2011, Václav et al. 2011, Berthier et al. 2012, Kiss et al. 2020). However, long-term responses of cavity-nesting fauna to nest-box supplementation are not well-known (Beyer and Goldingay 2006, Goldingay and Stevens 2009) and a number of studies reported inferior performance, e.g., lower breeding success or survival rate, of bird populations associated with nest boxes (Schlaepfer et al. 2002, Klein et al. 2007, Rodríguez et al. 2011, McClure et al. 2017). In addition to the effect of humaninduced landscape fragmentation, nest-box provisioning can also alter density and distribution of birds and their social interactions (Jones and Leopold 1967, Haramis and Thompson 1985, Duckworth et al. 2017, Catry and Catry 2019) that, in turn, may have negative consequences on health indices, reproduction, and survival (Newton 1998, Berthier et al. 2012). Availability of social information, i.e., presence and breeding performance of conspecifics, which is important also for breeding habitat choice (Danchin et al. 1998, Parejo et al. 2007, Václav et al. 2011, Stodola and Ward 2017), could be particularly sensitive to the alteration of species distributions and the disruption of information webs (Holt 2007, Schmidt et al. 2010).
There is a lack of studies on the relative importance of artificial and natural nest-site types in adult and offspring survival of cavity-nesting organisms (see Libois et al. 2012 for adult survival in a seabird species in nest-boxes and natural nests). We assess fitness consequences of cavity type associations with respect to apparent survival in a migratory non-excavator cavity-nesting bird species, the European Roller (Coracias garrulus). Because cavity type use can confound estimates of survival by affecting the degree of study area (site) fidelity (Lebreton et al. 1992), e.g., via the link with reproductive success (Greenwood and Harvey 1982), we examine whether site fidelity differs depending on cavity type use (c.f. Menzel 2018). Additionally, we explore if European Rollers show any persistence in their use of cavity type, i.e., habitat fidelity, because site fidelity can be an artefact of habitat choice that is independent of reproductive success (Patrick and Weimerskirch 2017).

The European Roller (hereafter roller) is of conservation concern in the last decades given its steep population declines throughout Europe (Tucker and Heath 1994, BirdLife International 2004). Rollers nest naturally in ephemeral tree and sandstone cavities excavated by other birds (Cramp 1998). Some population recoveries were locally achieved in some countries because of conservation actions involving nest-box deployment (e.g., Rodríguez et al. 2011, Václav et al. 2011, Monti et al. 2019, Kiss et al. 2020). Yet, nest-box provisioning can have unintended consequences for rollers, such as desertion of natural cavities (Valera et al. 2019) or increased intra- and inter-specific interference (Václav et al. 2011, Catry and Catry 2019).

We take advantage of a longitudinal study of a roller population where nest boxes have been provided as an additional nesting substrate during the last 15 years (see Valera et al. 2019). We studied apparent survival as well as site and habitat fidelity of birds associated with different cavity types. Specifically, we examine if apparent survival and the two fidelity measures vary between rollers breeding or hatching in nest-boxes, natural nests (sandstone burrows), and semi-natural nests, i.e., cavities in artificial structures such as putlog holes in bridges that are inadvertently provided for nesting. In addition, we investigate whether two social-ecological indices, breeding cluster size, and distances between clusters, contribute to explaining roller apparent survival rates. Previously, nest-boxes were reoccupied by rollers more frequently than natural and semi-natural nests during the early phase of the nest-box supplementation program (Václav et al. 2011). A recent study based on nest-entrance reduction has lent some support to the idea that nest-boxes represent a more suitable cavity type than sandstone burrows and stone cavities by providing increased protection from nest competitors and predators (Valera et al. 2019). Yet, nest reoccupancy was context dependent because it was higher under high local conspecific breeding density, with the density measure combining both cluster size and distance to neighbors (Václav et al. 2011). Conversely, breeding at high density could be costly for rollers because of intra- and inter-specific agonistic interactions (Václav et al. 2011, Catry and Catry 2019). Consequently, we predict that (1) apparent survival and site and/or habitat fidelity would be higher for nest-box rollers than for rollers breeding or hatching in other cavity types, and (2) apparent survival would increase with decreasing distances between breeding clusters, but decrease with increasing size of breeding clusters. 


\section{METHODS}

\section{Study system}

The population of rollers breeding in the Tabernas Desert (Almería, SE Spain, $37^{\circ} 05^{\prime} \mathrm{N}, 2^{\circ} 21^{\prime \prime} \mathrm{W}$ ) has been studied from 2004. The study area $\left(\sim 50 \mathrm{~km}^{2}\right)$ consisted of badlands with olive and almond groves interspersed among dry streambeds (ramblas) and steppe habitats. Rollers are non-excavator cavity-nesting birds, rearing a single brood per year (Cramp 1998). They are long-distance migrants that arrive at breeding grounds when resident, secondary cavity-nesting birds are already settled. Rollers in our study area breed in two geographically and ecologically distinct settings: (1) the Tabernas area, a lowland dominated by dry ramblas, and (2) the Uleila area, a hillier area dominated by steppe habitats (Fig. 1). Rollers nested predominantly in sandstone burrows and nest-boxes in the Tabernas area, whereas in the Uleila area rollers nested predominantly in stone cavities and nest-boxes. Each year we actively searched for roller pairs using any cavity type around known nest sites. Nest-boxes have been gradually deployed at the study area from 2005, but their number and occupancy rate varied between the two study localities (Fig. 2). Nest boxes were deployed across the whole study area, but their numbers varied locally according to the number of rollers nesting in natural and seminatural nest sites (Table 1). Nest boxes used along this study keep the same structure (quadrangular prism) and similar dimensions (height $\times$ length $\times$ width: $310 \times 232 \times 230 \mathrm{~mm}$, entrance diameter: $60 \mathrm{~mm}$, with a removable upper lid to allow nest monitoring). The vast majority of adult rollers in both areas bred in loose clusters comprising 2-26 breeding pairs (97\% [346/358] of marked adult rollers; only 12 marked rollers bred solitarily $862-2493 \mathrm{~m}$ from the nearest clustered breeders). Rollers breeding in the Tabernas area bred in larger and more densely spaced breeding clusters compared with rollers breeding in the Uleila area (Fig. 1).

Fig. 1. Map of the study area and the distribution of European Roller Coracias garrulus breeding clusters in two localities (Tabernas and Uleila). The size of individual clusters reflects maximum cluster size reached during the study period and ranges from 1 to 26 breeding pairs.

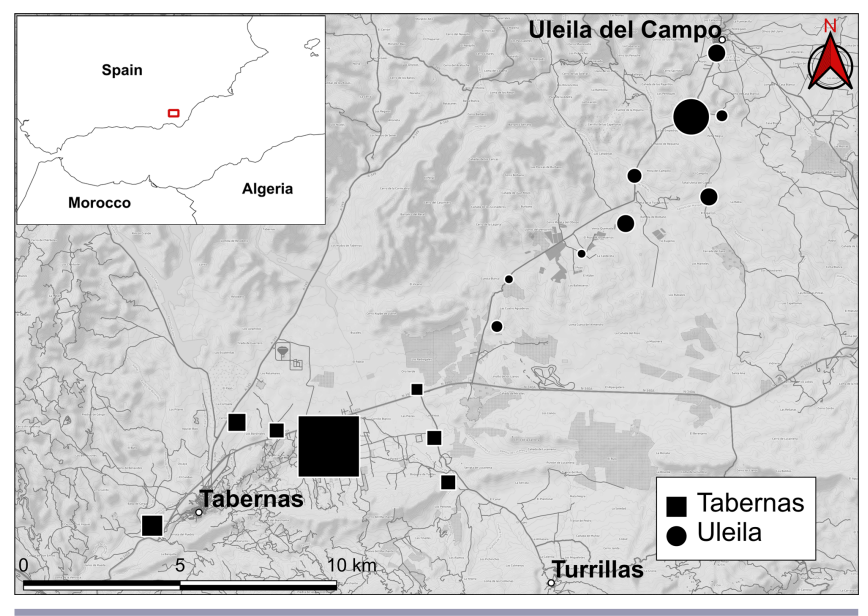

Fig. 2. Number of nest-boxes available (A) and their occupancy by European Rollers Coracias garrulus (B) in two study localities (Tabernas and Uleila) during 2005-2019.
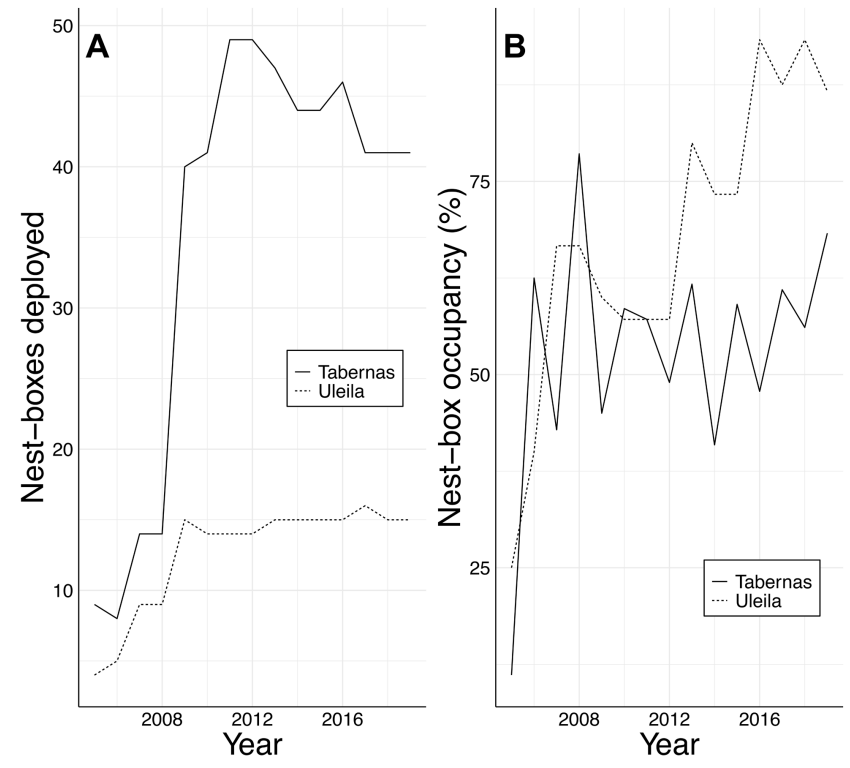

Table 1. Description of the structure of breeding clusters of the European Roller Coracias garrulus in two study localities within the study area in SE Spain, 2004-2019.

\begin{tabular}{lcc}
\hline \hline Breeding cluster & $\begin{array}{c}\text { Maximum yearly } \\
\text { number of occupied nest } \\
\text { boxes }\end{array}$ & $\begin{array}{c}\text { Maximum yearly number } \\
\text { of occupied natural and } \\
\text { semi-natural nest sites }\end{array}$ \\
\hline Uleila & 3 & 14 \\
$\# 1$ & 4 & 2 \\
$\# 2$ & 1 & 3 \\
$\# 3$ & 3 & 1 \\
$\# 4$ & 0 & 3 \\
$\# 5$ & 2 & 1 \\
$\# 6$ & 2 & 0 \\
$\# 7$ & 1 & 0 \\
$\# 8$ & 1 & 0 \\
$\# 9$ & & \\
Tabernas & 16 & 13 \\
$\# 1$ & 5 & 3 \\
$\# 2$ & 5 & 1 \\
$\# 3$ & 2 & 1 \\
$\# 4$ & 3 & 0 \\
$\# 5$ & 3 & 0 \\
$\# 6$ & 2 & 0 \\
$\# 7$ & & \\
\hline
\end{tabular}

\section{Capture-mark-recapture of rollers}

During 2004-2019, a total of 2266 individuals have been ringed with numbered aluminum rings (issued by the Spanish ringing scheme) on the left or right tarsus: 1908 individuals were ringed as nestlings (hatch year, HY) and 358 individuals as full-grown 
birds (after hatch year, AHY) at the active nests. Annually, we marked on average 119.3 ( \pm 56.7 SD) HY birds and $22.4 \pm 17.5$ AHY individuals. Most $(82.4 \%)$ of the birds captured as AHY individuals were putative parents captured at the nest with hand nets during the last stages of incubation. During 2005-2007, AHY birds were also captured at the nest with mist nets during feeding. Based on video monitoring of a few nest cavities (unpublished observations), in addition to putative parents, helpers and floaters might have been captured at some nests among feeding birds. No nest was deserted after capture and marking. In most years, both HY and AHY were captured and marked, but only nestlings were marked in 2004 and 2008 . The majority (92.7\%) of marked birds were sexed molecularly (Fridolfsson and Ellegren 1999) using a small blood sample ( 10-30 $\mu$ l) extracted from the brachial vein; the sex of the nestlings marked in 2004 and 2008, and not recaptured afterward, is not known because we did not collect blood samples in those two years. Of 2266 individuals marked during 2004-2019, 158 (7\%) were recaptured at least once over the subsequent years. Only live-trapped birds possessing aluminum rings were considered as "recaptures."

\section{Ecological predictors}

In addition to sex and age class (see above), we examined two categorical predictors of apparent survival: (1) cavity type (sandstone burrows, stone cavities, and nest-boxes), and (2) locality (Tabernas and Uleila). Because the type of cavity could have affected the catchability of rollers, cavity type also was considered as a predictor of recapture probability. In total, we marked 1310 (HY: 1117; AHY: 193) and 956 (HY: 791; AHY: 165) rollers in Tabernas and Uleila, respectively. In Tabernas, we marked 386, 35, and 889 rollers at sandstone burrows, stone cavities, and nest-boxes; in Uleila we marked 54, 473, and 429 rollers at sandstone burrows, stone cavities, and nest-boxes. We also examined the importance of three ecological covariates for apparent survival: (1) size of the breeding cluster (BCS) where the bird was marked, (2) distance to the nearest breeding cluster (DNBC) from the breeding cluster where the bird was marked, and (3) year. Roller breeding habitat patches were defined as distinct geomorphological units: (1) ramblas (dry stream channels with steep sandstone banks), which are linear, continuous geographical units separated from neighboring ramblas by hills, olive tree orchards, and human settlements, (2) individual bridges with numerous, densely spaced cavities ( 2-3 m apart), and (3) spatial aggregations of suitable nesting substrates: sparsely located trees, small sandstone banks, and isolated country houses. Breeding clusters were defined as the sets of breeding pairs within such habitat patches with frequent social interactions such as courtship displays or joint defense from nest predators or competitors (see also Václav et al. 2011). DNBC was calculated as the distance between nearest nests for two neighboring clusters. Considering 358 marked adult rollers, BCS and DNBC reached on average 12.68 ( $\pm 8.68 \mathrm{SD})$ breeding pairs and $1268.77 \pm 762.42$ $\mathrm{m}$ in Tabernas and $6.27 \pm 4.23$ breeding pairs and $1439.11 \pm 522.84$ $\mathrm{m}$ in Uleila, respectively. Finally, the importance of year was assessed to address inter-annual variation in apparent survival.

\section{Residency analysis}

To examine natal and breeding site fidelity (sensu Pearce 2007, in our case the study area including both localities, Tabernas and Uleila), the capture history of rollers marked from 2004 to 2017 was analyzed to categorize birds based on three indices: (1) absolute recapture rates, (2) annual recapture rates, and (3) absolute recapture rates in consecutive years. These indices were chosen to account for a relatively short roller generation length of 5.6 years (BirdLife International 2015), thus lending a similar importance to indices based on absolute (indices 1 and 3) and relative (index 2) capture rates. The maximum capture period for rollers marked as AHY and HY was 10 and 11 years, respectively. Therefore, we assumed the maximum life-history period to be 10 and 11 years for the two age classes with respect to index 2. Also, given the length of the maximum life-history period, i.e., 10 and 11 years, absolute recapture rates in consecutive years (index 3 ) were used to better distinguish between regular and irregular visitors to the study area. Rollers normally start to breed at the age of two years, i.e., in the third calendar year (Glutz von Blotzheim and Bauer 1980). Indeed, most (27/66) of recaptured rollers marked as HY were recaptured for the first time two years after marking $(1,13$, and 25 of 66 recaptured HY rollers were recaptured for the first time 1,3 , and $>3$ years after marking). Because it is very unlikely to recapture 2-yr-old rollers as breeders at the nest, we allowed a gap of one year after marking when calculating index 3 for rollers marked as HY. Site fidelity for rollers of both age classes was examined only considering birds marked at the latest in 2017 to increase categorization accuracy based on the three indices. We used agglomerative hierarchical cluster (AHC) analysis to categorize rollers based on the three site fidelity indices using the hclust function in $\mathrm{R}$ (version 3.5.2, R Core Team 2018). This analysis has been previously used to examine site fidelity in different vertebrates based on recapture data (e.g., Schleimer et al. 2019). Data for all indices were standardized to the median and the median absolute deviation before AHC to examine the three indices on the same scale. Ward's method (ward. D2 in hclust) was chosen as the clustering algorithm and Euclidean distance was applied as a measure of dissimilarity between clusters (Murtagh and Legendre 2014). A dendrogram was produced to visualize results of AHC analysis to distinguish rollers that were regularly recaptured during the study period from those that were sparsely or never recaptured. The data for 316 and 1452 rollers marked as AHY and HY birds, respectively, was used for residency analysis, involving only birds with known sex.

Considering 158 individuals (92 AHY and 66 HY birds) of known sex that were recaptured at least once during the period 2004 2019, habitat fidelity also was examined. Herein, we studied whether birds captured for the first time as nestlings or breeders in a specific cavity type were subsequently recaptured in the same or different cavity type. In total, we recorded 215 recaptures for the 158 individuals: 149 and 66 recaptures for AHY and HY birds, respectively. Only the first recapture of rollers marked as HY birds was included in the data set for HY birds, with subsequent recaptures of such birds included in the data set of AHY birds. Unlike for site fidelity, habitat fidelity was examined considering recaptures during the entire study period.

\section{Survival analysis}

We estimated apparent survival and recapture probability between successive breeding seasons with the RMark package v. 2.2.6 (Laake 2013) in R v. 3.5.2 (R Core Team 2018). The RMark package provides an interface to the software package MARK (Cooch and White 2019). To analyze our live encounter data, we 
used the Cormack-Jolly-Seber (CJS) model (Lebreton et al. 1992). Using the CJS models, we fitted our data to models including two parameters: apparent survival $(\phi)$ and recapture probability $(p)$. Before analysis we tested our data using the goodness-of-fit (GOF) tests implemented in the program U-CARE (Choquet et al. 2009), using the package R2ucare v. 1.0.0 (Gimenez et al. 2017). Because the use of cavity types by rollers is confounded by the locality of our study area (Tabernas and Uleila), which means that models including both cavity type and locality are not meaningful, we tested the fit of our data for two global models: $\phi(\sim$ age*sex*time+age*locality*time $) p$ (nest*time) and $\phi(\sim$ age* sex*time+age*nest*time) $p$ (nest*time). We did not include the full interaction term involving age, sex, locality/nest type, and time for $\phi$ parameters because of estimability problems for some of the parameters. Considering four GOF tests for single-site/state models, we tested the assumptions about the probability of recapture (Tests 2.CT and 2.CL) and survival (Tests 3.SR and 3. $\mathrm{SM}$ ). Conducting the four tests for each categorical predictor (age class, sex, cavity type, and locality), GOF testing revealed the violation of the assumption that newly encountered individuals have the same chance to be later reobserved as recaptured individuals (Test 3.SR, age class: $\mathrm{HY}, \mathrm{P}<0.001$, $\mathrm{AHY}, \mathrm{P}=0.86$; sex: female, $\mathrm{P}<0.001$, male, $\mathrm{P}<0.001$; cavity type: stone cavity, $\mathrm{P}=0.78$, sandstone burrows, $\mathrm{P}=0.01$, nest-boxes, $\mathrm{P}<0.001$; locality: Tabernas, $\mathrm{P}<0.001$, Uleila, $\mathrm{P}<0.001)$. To address the violation of the part of the assumption on the same probability of survival, "transience" models where time-dependence is analyzed in both age classes can be used (Pradel et al. 1997). However, such transience models were not feasible because of estimability problems. Consequently, we only considered timeinvariant models for $\phi$ estimation given our data (e.g., Cooch and White 2019). Nevertheless, we considered year as a linear and quadratic covariate in models including covariates to see if apparent survival varied inter-annually. Finally, the global GOF tests and Fletcher $\hat{c}$ values, which are provided with all models by the RMark package, were calculated for both global models. Fletcher $\hat{c}$ values suggest a satisfactory fit for both global models ( $\hat{c}=0.998$ for both models). Therefore, we did not account for the lack of fit in our models and compared the candidate models based on their $\mathrm{AIC}_{c}$ and deviance $(D)$ values (Burnham and Anderson 2002). We conducted survival modeling in two steps. In the first step, we estimated apparent survival and recapture probability by considering categorical predictors only (age class, sex, cavity type, and locality; e.g., Burnham and Anderson 2002). For both the apparent survival and the recapture probability term, we examined the fit of models involving all possible combinations of additive and interactive effects derived from the parametric structure of the two global models. In the second step, we examined the fit of the models from the previous step, which included the three covariates (BCS, DNBC, and year). Year has been analyzed as a linear or a quadratic term to account for the potential non-linear relationship between apparent survival and time. The covariates were examined in candidate models one at a time to address the correlation between BCS and DNBC (Kendall's rank correlation: $\tau=-0.30, \mathrm{z}=-20.44, \mathrm{P}<0.001$ ). To facilitate the interpretation of results, all covariates were centered and standardized to have their mean at zero and to be on the same scale. To assess which models fitted our data best, we used the information-theory (IT) method (Burnham and Anderson 2002, Burnham et al. 2011). We inspected the following indices for each model: number of parameters $(K), \mathrm{AIC}_{c}, \mathrm{AIC}_{c}$ differences $\left(\Delta_{i}\right)$, Akaike weights $\left(\varpi_{i}\right)$, deviance $(D)$, model likelihood $(M L)$, evidence ratio $(E R)$, and Fletcher $\hat{c}(\hat{c})$. Because models with $\Delta_{i} \leq$ 6 can be considered to fit data comparably well (Richards 2008), we followed the recommendations by Symonds and Moussalli (2011), classifying models with $\Delta_{i} \leq 2$ as the best models but considering models having a $\Delta_{i}$ value $\leq 6$ as plausible. We evaluated the IT indices for all plausible models, but derived the inference about the importance of individual predictors for the top models that showed approximately the same empirical support in terms of $E R$. Finally, for models including covariates, we considered any covariate as important only if the $E R$ value of the model including the covariate was $\geq 10$ than that of the same model without the covariate (Lukacs et al. 2007).

\section{RESULTS}

\section{Natal and breeding site fidelity}

AHC analysis identified two groups of rollers for both age classes based on three site fidelity indices. Based on this analysis, the group of regularly recaptured rollers (hereafter regulars) is characterized by at least one recapture sequence without a gap for consecutive years or by at least one recapture sequence with maximum one year gap but with the annual recapture rate $>18 \%$. The other group comprised rollers that were never or occasionally recaptured; their recapture sequence is not gapless and the annual recapture rate is $<18 \%$. With respect to 316 rollers marked as adults (AHY), AHC identified a cluster of 74 (23.4\%) regulars and 242 rollers representing occasional visitors (Fig. 3). Of 242 rollers from the latter group, 16 rollers were recaptured once and 226 were never recaptured. Of 1452 rollers marked as nestlings (HY), $39(2.7 \%)$ rollers represented regulars; the other group comprised 1386, 26, and 1 roller that were recaptured zero, one, and two times, respectively (Fig. 4). Of rollers recaptured at least once, regulars were significantly more frequent among rollers marked as adults compared with rollers marked as HY birds (Fisher's exact test: $\mathrm{P}=0.002$ ).

Regular visitors at the study site were significantly more frequently associated with nest-boxes than with other nest types (sandstone burrows and stone cavities), but this applied only to rollers marked as adults (AHY birds: $\mathrm{P}=0.003$; $\mathrm{HY}$ birds: $\mathrm{P}=$ 0.14). Closer examination of the data shows that the latter result was due to adult males, but not adult females, that were more frequently associated with nest-boxes than with other nest types (AHY males: $\mathrm{P}=0.003$; AHY females: $\mathrm{P}=0.23$; $\mathrm{HY}$ males: $\mathrm{P}=$ 0.16 ; HY females: $\mathrm{P}=0.58$ ).

We did not find differences in the frequencies of regulars depending on the locality for either age class (AHY birds: $\mathrm{P}>$ 0.99; HY birds: $\mathrm{P}=0.14$ ). However, among $\mathrm{HY}$ females, regulars hatching in Tabernas were significantly more frequent than those hatching in Uleila (AHY males: $\mathrm{P}=0.53$; AHY females: $\mathrm{P}=0.60$; HY males: $\mathrm{P}=0.84$; HY females: $\mathrm{P}=0.02$ ).

Over the whole study period of 16 years, no roller marked as a breeder was recaptured outside the locality of marking. In contrast, 10 rollers marked as nestlings were recaptured outside their original locality of marking: 2 males and 2 females moved from Tabernas to Uleila, whereas 5 males and 1 female moved from Uleila to Tabernas. 
Fig. 3. Dendrogram of agglomerative hierarchical cluster (AHC) analysis based on three site fidelity indices for adult (AHY) European Rollers Coracias garrulus. Birds from the high site fidelity group (regulars; red) were regularly recaptured at the study site, while the low site fidelity group (other birds; blue) comprised birds that were occasionally or never recaptured.

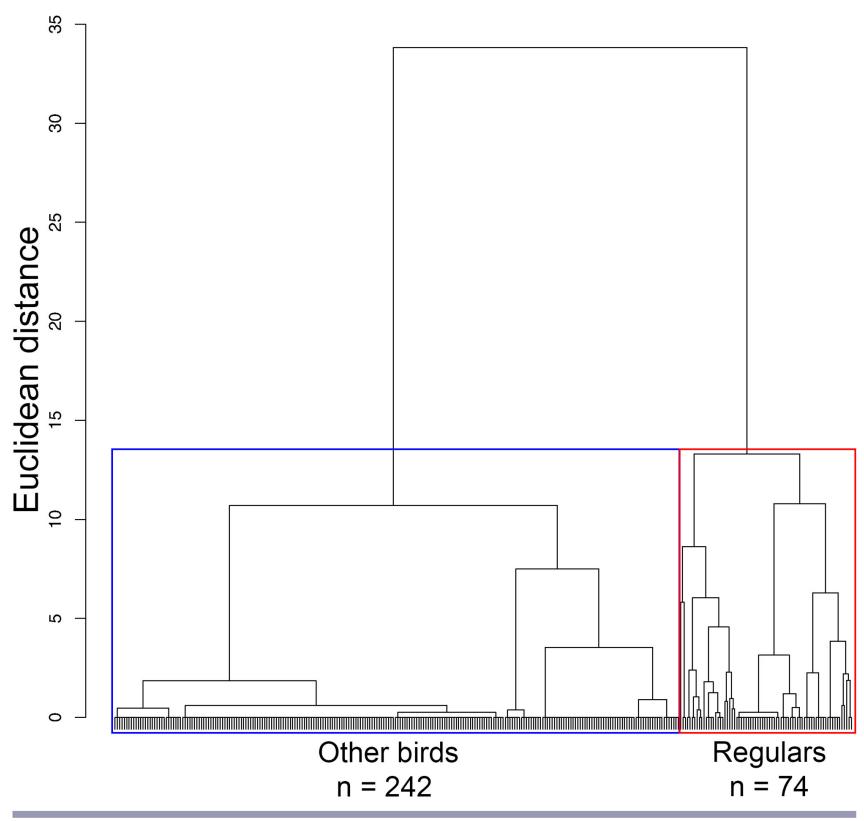

Fig. 4. Dendrogram of agglomerative hierarchical cluster (AHC) analysis based on three site fidelity indices for juvenile (HY) European Rollers Coracias garrulus. Birds from the high site fidelity group (regulars; red) were regularly recaptured at the study site, while the low site fidelity group (other birds; blue) comprised birds that were occasionally or never recaptured.

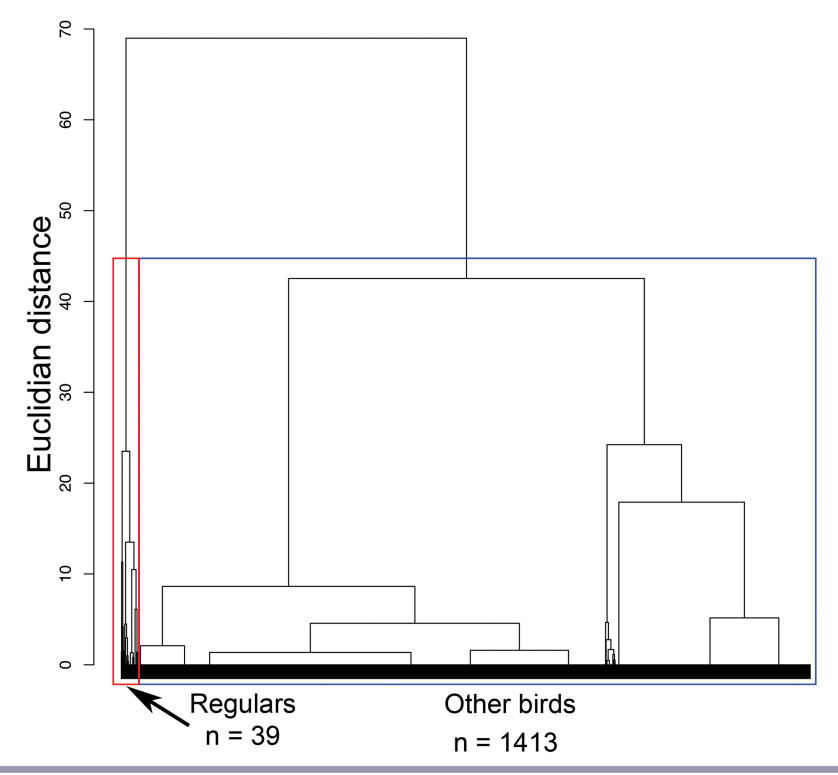

\section{Habitat (cavity type) fidelity}

Adult rollers breeding in nest-boxes were subsequently more frequently recaptured as breeders in the same cavity type compared with adult rollers marked in other cavity types (Fisher's exact test: nest-boxes, 89/95 vs. non-nest-boxes, 42/54, $\mathrm{P}=0.008$ ). The difference was driven by low fidelity by non-nest-box males (males: nest-boxes, 40/41 vs. non-nest-boxes, 15/22, $\mathrm{P}=0.002$; females: $49 / 54$ vs. $27 / 32, \mathrm{P}=0.49$ ). Rollers marked as nestlings in nest-boxes also were subsequently more frequently recaptured as breeders in the same cavity type compared with HY rollers marked in other cavity types (nest-boxes, $31 / 42$ vs. non-nest-boxes, 10/24, $\mathrm{P}=0.02$ ). In contrast to adult rollers, the difference in HY rollers seemed to have occurred because of low fidelity by non-nest-box females, and not males (males: nest-boxes, 21/27 vs. non-nestboxes, $8 / 15, \mathrm{P}=0.16$; females: $10 / 15$ vs. $2 / 9, \mathrm{P}=0.09$ ).

\section{Apparent survival}

None of the candidate models can be classified as superior based on model probability (Akaike weights, $w_{i}$ ) or evidence ratio ( $E R$; Table 2). Specifically, 14 top models show $E R$ values within 10 and can therefore be considered to have comparable empirical support. The two top models (their $E R \approx 1$ ) indicate that apparent survival of rollers is most parsimoniously explained by age class and sex and the recapture probability is most parsimoniously explained by time. The remaining 12 models differ from the two top models by the inclusion of locality or cavity type in the term explaining apparent survival and/or by the inclusion of cavity type in the term on recapture probability, respectively. The exception is model \#4, which only includes age class in the term explaining apparent survival and time in the term explaining recapture probability. These results indicate that, given our data, locality and cavity type add little to the explanatory power of the top models including age class and sex in the term on apparent survival. Also, even though the most parsimonious model \#4, which only includes age class in the survival term, is comparable to the two top models ( $\Delta_{i}$ is $\left.\leq 2\right)$, the empirical support for the two top models is approximately two times higher than that for model \#4 (Table 2). The important contribution of sex in two top models points to the fact that although the apparent survival in adult (AHY) birds is almost indistinguishable between sexes (model $\phi_{\text {age* }{ }^{2} \text { sex }}, p_{\text {time }}$, estimates $[95 \%$ CI $]$, AHY males: $70.26 \%$ [64.54-75.41], AHY females: 69.32\% [63.59-74.51]), juvenile(HY) females appear to show lower apparent survival than HY males (HY males: 13.43\% [9.65-18.39], HY females: 7.57\% [4.98-11.36]).

\section{Apparent survival including covariates}

After including the covariates year, BCS, and DNBC in the survival term, we obtained analogous results to the ones without covariates. We obtained 15 comparable top models, which involve two top models with age and sex in the survival term and the other models including locality or cavity type in the survival term and/ or cavity type in the term on recapture probability (Table 3 ). Importantly, 14 of 15 top models included covariate DNBC and model \#15 included covariate BCS. Because the empirical support for the two top models with the covariate DNBC is more than 10 times higher than that for the same models without the covariate (Table 3), our results suggest moderate support for the effect of DNBC on apparent survival. Our results consistently reveal that apparent survival decreases with increasing DNBC. Based on the top model $\left(\phi_{\mathrm{age} * \mathrm{sex}+\mathrm{DNBC}}, p_{\text {time }}\right)$ and back-transformed data, we 
Table 2. A summary of 19 models on the apparent survival $(\Phi)$ and the recapture probability (p) of the European Roller Coracias garrulus in SE Spain, 2004-2019. The following group factors were examined: age class (hatching year [HY] and after hatching year [AHY]), sex, locality (Tabernas and Uleila), nest type (sandstone burrows, stone cavities, and nest-boxes). Number of parameters $(K)$, $\operatorname{AIC}_{c}, \operatorname{AIC}_{c}$ differences $\left(\Delta_{i}\right)$, Akaike weights $\left(\omega_{i}\right)$, deviance $(D)$, model likelihood $(M L)$, evidence ratio $(E R)$, and Fletcher $\hat{\mathrm{c}}(\hat{\mathrm{c}})$ are shown for each model. Models with $\Delta_{i}<6$ are displayed.

\begin{tabular}{|c|c|c|c|c|c|c|c|c|c|}
\hline \# & Model & $K$ & $\mathrm{AIC}_{c}$ & $\Delta_{i}$ & $\omega_{i}$ & $D$ & $M L$ & $E R$ & $\hat{\mathrm{c}}$ \\
\hline 1 & $\phi(\sim$ age* $\operatorname{sex}) p(\sim$ time $)$ & 19 & 1687.98 & 0 & 0.20 & 845.29 & 1 & 1.00 & 0.99 \\
\hline 2 & $\phi(\sim$ age $+\operatorname{sex}) p(\sim$ time $)$ & 18 & 1688.57 & 0.59 & 0.15 & 847.91 & 0.75 & 1.34 & 0.99 \\
\hline 3 & $\phi(\sim a g e *$ sex + locality $) p(\sim$ time $)$ & 20 & 1689.73 & 1.75 & 0.08 & 845.00 & 0.42 & 2.40 & 0.99 \\
\hline 4 & $\phi(\sim$ age $) p(\sim$ time $)$ & 17 & 1689.75 & 1.77 & 0.08 & 851.13 & 0.41 & 2.42 & 0.99 \\
\hline 5 & $\phi(\sim$ age + locality $+\operatorname{sex}) p(\sim$ time $)$ & 19 & 1690.29 & 2.30 & 0.06 & 847.59 & 0.32 & 3.16 & 0.99 \\
\hline 6 & $\phi(\sim$ age*sex $) p(\sim$ nest + time $)$ & 21 & 1690.35 & 2.36 & 0.06 & 843.58 & 0.31 & 3.26 & 0.99 \\
\hline 7 & $\phi(\sim$ age + sex $) p(\sim$ nest + time $)$ & 20 & 1690.93 & 2.94 & 0.05 & 846.20 & 0.23 & 4.36 & 0.99 \\
\hline 8 & $\phi(\sim$ age*sex + age*locality $) p(\sim$ time $)$ & 21 & 1691.43 & 3.45 & 0.04 & 844.67 & 0.18 & 5.61 & 0.99 \\
\hline 9 & $\phi(\sim a g e *$ sex + nest $) p(\sim$ time $)$ & 21 & 1691.47 & 3.49 & 0.04 & 844.71 & 0.17 & 5.73 & 0.99 \\
\hline 10 & $\phi(\sim$ age + locality $) p(\sim$ time $)$ & 18 & 1691.56 & 3.58 & 0.03 & 850.91 & 0.17 & 5.98 & 0.99 \\
\hline 11 & $\phi(\sim$ age + nest $+\operatorname{sex}) p(\sim$ time $)$ & 20 & 1691.98 & 3.99 & 0.03 & 847.25 & 0.14 & 7.37 & 0.99 \\
\hline 12 & $\phi(\sim$ age*locality+sex $) p(\sim$ time $)$ & 20 & 1692.06 & 4.08 & 0.03 & 847.34 & 0.13 & 7.70 & 0.99 \\
\hline 13 & $\phi\left(\sim\right.$ age* ${ }^{*}$ sex + locality $) p(\sim$ nest + time $)$ & 22 & 1692.08 & 4.10 & 0.03 & 843.27 & 0.13 & 7.77 & 0.99 \\
\hline 14 & $\phi(\sim$ age $) p(\sim$ nest+time $)$ & 19 & 1692.13 & 4.15 & 0.03 & 849.44 & 0.13 & 7.96 & 0.99 \\
\hline 15 & $\phi(\sim$ age + locality $+\operatorname{sex}) p(\sim$ nest + time $)$ & 21 & 1692.62 & 4.64 & 0.02 & 845.85 & 0.10 & 10.16 & 0.99 \\
\hline 16 & $\phi(\sim a g e+$ nest $) p(\sim$ time $)$ & 19 & 1693.30 & 5.31 & 0.01 & 850.61 & 0.07 & 14.25 & 0.99 \\
\hline 17 & $\phi(\sim$ age*locality $) p(\sim$ time $)$ & 19 & 1693.31 & 5.33 & 0.01 & 850.62 & 0.07 & 14.35 & 0.99 \\
\hline 18 & $\phi(\sim$ age $*$ sex + age*locality $) p(\sim$ nest + time $)$ & 23 & 1693.78 & 5.80 & 0.01 & 842.93 & 0.06 & 18.15 & 0.99 \\
\hline 19 & $\phi(\sim$ age + locality $) p(\sim$ nest + time $)$ & 20 & 1693.93 & 5.95 & 0.01 & 849.21 & 0.05 & 19.61 & 0.99 \\
\hline
\end{tabular}

found that from the lowest to the highest values of DNBC the apparent survival dropped by about $25 \%$ and $50 \%$ for AHY and HY rollers, respectively (apparent survival at DNBC 839, 1216, 1811, 2686, and $4312 \mathrm{~m}: \mathrm{AHY} / \mathrm{HY}$ males: 73.87/15.26, 70.08/12.98, 65.76/10.90, 61.16/9.11, and 55.38/7.33\%; AHY/HY females: 72.78/8.78, 68.89/7.39, 64.49/6.14, 59.83/5.09, and $54.00 / 4.06 \%$ [Fig. 5]). Finally, inspection of the model results reveals that while decreases in apparent survival with increasing DNBC were comparable for AHY males and females, apparent survival was distinctly higher for HY males than for HY females, but only at short DNBCs (Fig. 5).

\section{DISCUSSION}

Supplementation of nest-boxes and other artificial nest types is increasingly used as a conservation measure for a variety of cavitynesting organisms. Our study provides information on apparent survival and residency patterns of a cavity-nesting bird species breeding in nest-boxes as well as natural and semi-natural cavities. We found that social-ecological factors were relatively more important than physical characteristics of nest sites on apparent survival. Nonetheless, our results suggest that the type of cavity in which rollers hatched or nested has important consequences for the fidelity to the study area and cavity type.

\section{Site and habitat fidelity patterns}

Fidelity to natal and breeding sites is traditionally viewed as an adaptive response to heterogeneous environmental conditions and may be used as an indicator of the quality of these sites (Pärt 1991, Kokko and Sutherland 2001, Davis and Stamps 2004, Schmidt 2004). Our study area is seemingly suitable for rollers, because predation rate is low and breeding performance is generally high there (unpublished data). In contrast to a neighboring declining roller breeding population in Granada
Fig. 5. Apparent survival in European Rollers Coracias garrulus as a function of sex, age class (HY and AHY), and distance to nearest breeding cluster. Apparent survival probability $\pm \mathrm{SE}$ were estimated from model $\Phi_{\mathrm{age} *_{\mathrm{sex}}+\mathrm{DNBC}} p_{\text {time }}$. Apparent survival and distance to nearest breeding cluster are shown on the original scale after back-transformation.

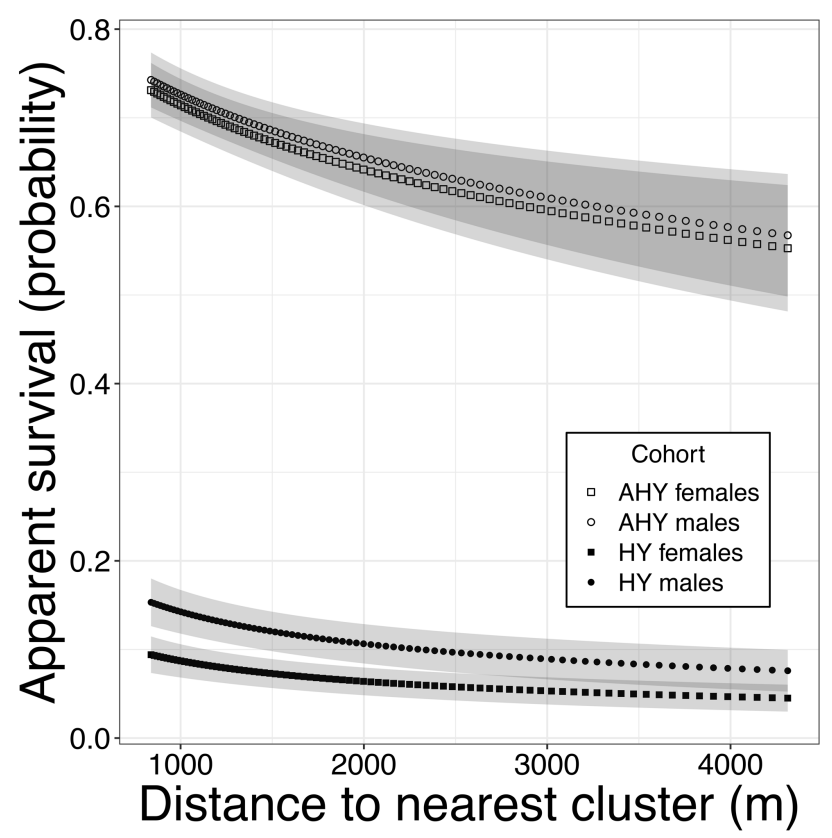


Table 3. A summary of 20 models, including covariates, on the apparent survival $(\Phi)$ and the recapture probability (p) of the European Roller Coracias garrulus in SE Spain, 2004-2019. The following group factors were examined: age class (hatching year [HY] and after hatching year [AHY]), sex, locality (Tabernas and Uleila), and nest type (sandstone burrows, stone cavities, and nest-boxes). The following covariates were examined: distance to nearest breeding cluster (DNBC), breeding cluster size (BCS), and year. Number of parameters $(K), \mathrm{AIC}_{c}, \mathrm{AIC}_{c}$ differences $\left(\Delta_{i}\right)$, Akaike weights $\left(\omega_{i}\right)$, deviance $(D)$, model likelihood $(M L)$, evidence ratio $(E R)$, and Fletcher $\hat{\mathrm{c}}(\hat{\mathrm{c}})$ are shown for each model. Models with $\Delta_{i}<6$ are displayed.

\begin{tabular}{|c|c|c|c|c|c|c|c|c|c|}
\hline$\#$ & Model & $K$ & $\mathrm{AIC}_{\text {, }}$ & $\Delta_{i}$ & $\omega_{i}$ & $D$ & $M L$ & $E R$ & $\hat{c}$ \\
\hline 1 & $\phi(\sim a g e * \operatorname{sex}+\mathrm{DNBC}) p(\sim$ time $)$ & 20 & 1682.36 & 0.00 & 0.17 & 1641.97 & 1.00 & 1.00 & 1.09 \\
\hline 2 & $\phi(\sim$ age + sex + DNBC $) p(\sim$ time $)$ & 19 & 1682.72 & 0.36 & 0.14 & 1644.36 & 0.84 & 1.20 & 1.09 \\
\hline 3 & $\phi(\sim a g e+\mathrm{DNBC}) p(\sim$ time $)$ & 18 & 1683.99 & 1.63 & 0.08 & 1647.67 & 0.44 & 2.25 & 1.09 \\
\hline 4 & $\phi(\sim$ age $*$ sex + locality $+\mathrm{DNBC}) p(\sim$ time $)$ & 21 & 1684.29 & 1.93 & 0.07 & 1641.86 & 0.38 & 2.62 & 1.09 \\
\hline 5 & $\phi(\sim$ age + sex + locality + DNBC $) p(\sim$ time $)$ & 20 & 1684.66 & 2.30 & 0.05 & 1644.27 & 0.32 & 3.16 & 1.09 \\
\hline 6 & $\phi(\sim$ age*sex $+\mathrm{DNBC}) p(\sim$ nest + time $)$ & 22 & 1684.72 & 2.35 & 0.05 & 1640.24 & 0.31 & 3.25 & 1.09 \\
\hline 7 & $\phi(\sim$ age + sex $+\mathrm{DNBC}) p(\sim$ nest + time $)$ & 21 & 1685.04 & 2.68 & 0.05 & 1642.61 & 0.26 & 3.82 & 1.09 \\
\hline 8 & $\phi(\sim a g e *$ sex + nest + DNBC $) p(\sim$ time $)$ & 22 & 1685.76 & 3.39 & 0.03 & 1641.28 & 0.18 & 5.46 & 1.10 \\
\hline 9 & $\phi(\sim$ age $*$ sex + age* locality $+\mathrm{DNBC}) p(\sim$ time $)$ & 22 & 1685.84 & 3.48 & 0.03 & 1641.36 & 0.18 & 5.69 & 1.09 \\
\hline 10 & $\phi(\sim$ age + locality $+\mathrm{DNBC}) p(\sim$ time $)$ & 19 & 1685.86 & 3.50 & 0.03 & 1647.50 & 0.17 & 5.74 & 1.09 \\
\hline 11 & $\phi(\sim$ age + sex + nest + DNBC $) p(\sim$ time $)$ & 21 & 1686.01 & 3.64 & 0.03 & 1643.57 & 0.16 & 6.19 & 1.10 \\
\hline 12 & $\phi(\sim$ age $*$ locality + sex + DNBC $) p(\sim$ time $)$ & 21 & 1686.30 & 3.94 & 0.02 & 1643.87 & 0.14 & 7.16 & 1.09 \\
\hline 13 & $\phi(\sim$ age $+\mathrm{DNBC}) p(\sim$ nest+time $)$ & 20 & 1686.34 & 3.98 & 0.02 & 1645.95 & 0.14 & 7.30 & 1.09 \\
\hline 14 & $\phi(\sim a g e *$ sex + locality+DNBC $) p(\sim$ nest+time $)$ & 23 & 1686.64 & 4.28 & 0.02 & 1640.13 & 0.12 & 8.51 & 1.09 \\
\hline 15 & $\phi(\sim a g e *$ sex + BCS $) p(\sim$ time $)$ & 20 & 1686.80 & 4.44 & 0.02 & 1646.40 & 0.11 & 9.18 & 1.08 \\
\hline 16 & $\phi(\sim a g e+$ sex + locality + DNBC $) p(\sim$ nest + time $)$ & 22 & 1686.99 & 4.63 & 0.02 & 1642.52 & 0.10 & 10.12 & 1.09 \\
\hline 17 & $\phi(\sim$ age + nest $+\mathrm{DNBC}) p(\sim$ time $)$ & 20 & 1687.42 & 5.06 & 0.01 & 1647.03 & 0.08 & 12.54 & 1.09 \\
\hline 18 & $\phi(\sim$ age + sex $+\mathrm{BCS}) p(\sim$ time $)$ & 19 & 1687.52 & 5.16 & 0.01 & 1649.17 & 0.08 & 13.21 & 1.08 \\
\hline 19 & $\phi(\sim a g e * \operatorname{sex}) p(\sim$ time $)$ & 19 & 1687.98 & 5.62 & 0.01 & 845.29 & 0.06 & 16.62 & 0.99 \\
\hline 20 & $\phi(\sim a g e+$ locality $+\mathrm{DNBC}) p(\sim$ nest+time $)$ & 21 & 1688.20 & 5.84 & 0.01 & 1645.77 & 0.05 & 18.57 & 1.09 \\
\hline
\end{tabular}

province (Rodríguez-Ruiz et al. 2020), our study population is relatively stable (Valera et al. 2019). Thus, we would expect relatively high site fidelity in such a population. Yet, our results revealed that only about $25 \%$ of rollers marked as breeders and $3 \%$ of rollers marked as nestlings displayed fidelity to their breeding and natal sites, respectively. It is possible that low site fidelity could be due to exchanges of rollers among neighboring populations. Surprisingly, however, over the period of 15 years, no roller marked in our study area has been recaptured elsewhere. Moreover, in spite of a short distance $(<100 \mathrm{~km})$ between our study population and the one studied by Rodríguez-Ruiz et al. (2020) and despite intensive and long-term ringing in the two study areas, no exchange of ringed rollers has been recorded between them. Finally, even within our study area, we found that only $6 \%(10 / 158)$ of recaptured rollers, all of them marked as nestlings, moved between the two adjoining study localities. The seemingly low site fidelity by both adult and juvenile rollers can be confounded by relatively high mortality rates of rollers during migration (Tokody et al. 2017).

Higher breeding than natal site fidelity detected in our roller study population agrees with the general pattern detected for other birds (Paradis et al. 1998). Also, Rodríguez-Ruiz et al. (2020) found that older rollers were more faithful to their breeding site than younger ones, but noted that, at least for males, the effect of age on breeding site fidelity could be due to higher reproductive success of older than younger rollers. We found that breeding site fidelity was associated with cavity type, so that males breeding in nest-boxes were more likely to be recaptured at the study site over consecutive years compared with males breeding in natural and semi-natural nests. Moreover, adult males breeding in nest-boxes were more frequently recaptured in subsequent years in the same cavity type compared with males breeding in other cavity types.
Previously, we found that sandstone burrows and bridge cavities were re-occupied over consecutive years less frequently than nestboxes and that, in contrast to nest-boxes, their reuse was dependent on their long-term use (Václav et al. 2011). These results point to (1) male-driven nest-site selection in rollers, and (2) a higher propensity of male rollers to come back to nest-boxes in their previously used breeding areas.

We found that males marked as nestlings appeared to show higher apparent survival if their natal sites were located in more densely spaced breeding clusters (Fig. 5). We cannot exclude the possibility that this result of apparent survival emerged through natal fidelity rather than true survival, an assertion consistent with the finding of higher natal fidelity of young females from the study locality showing larger and more densely spaced clusters. Interestingly, Rodríguez-Ruiz et al. (2020) found that males that were faithful to their breeding site appeared to show an attraction for low local conspecific breeding density. These seemingly contrasting results could arise as an artefact of low breeding densities in the population studied by Rodríguez-Ruiz et al. (2020), making it difficult to unmask the positive social effects on breeding habitat selection. Alternatively, it is possible that more crude social information, e.g., local conspecific density, is important for rollers' settlement decisions without prior breeding experience, while more refined social information, e.g., conspecific breeding success or interference competition, is important for males with breeding experience. An increased effort is needed to understand the drivers of natal fidelity because the cohort of first-time breeders is spatially more flexible in settlement decisions than birds with breeding experience and the dispersal rates of the former can be responsible for the species' population stability and persistence. 


\section{Individual predictors of apparent survival and recapture}

Apparent survival of rollers is most parsimoniously explained by individual characteristics, namely age and sex, and the recapture probability is most parsimoniously explained by time. Age was the most important factor accounting for apparent survival and, as expected (Maness and Anderson 2013), adult birds showed higher apparent survival than juveniles. However, in contrast to the usually relatively higher mortality rates observed for females (Payevsky 2016), we found that apparent survival of adult males and females was comparable. In contrast, females marked as nestlings showed lower apparent survival than their male counterparts. The importance of this interaction effect of sex and age on apparent survival was consistently revealed in models with and without covariates. These results accord with those for European Bee-eaters (Merops apiaster) and some other birds with juvenile males being more likely to return than juvenile females to their natal sites (see Lessells et al. 1994).

Our results on apparent survival of rollers corroborate the recent results by Rodríguez-Ruiz et al. (2020) in that adults display higher apparent survival than juveniles. However, unlike the latter authors we found sex-related differences in apparent survival of young rollers. Specifically, we found that apparent survival of juvenile males was almost two times higher than that of juvenile females. Further work is needed to highlight whether these discrepancies between populations reflect their different trends and can be attributed to different immigration and/or emigration rates (Lebreton et al. 1992).

\section{Physical and social-ecological predictors of apparent survival and recapture}

Studying the effect of nest type on demographic parameters is important because phenomena like nest type imprinting (see Brown and Collopy 2013 and references therein) or high breeding densities in nest-box populations (Mänd et al. 2005) could have detrimental conservation consequences. Valera et al. (2019) showed that rollers gradually abandon nesting in natural and semi-natural cavities in favor of nest-boxes. Thus, knowing the long-term effects of nest-boxes is required for informed conservation actions. We predicted a positive effect of nest-boxes on apparent survival because they were re-occupied more frequently than natural and semi-natural cavities (Václav et al. 2011) and offer safer sites from predators and competitors (Valera et al. 2019). However, despite the seemingly higher attractiveness of nest-boxes (see above), rollers breeding in these nests did not show higher apparent survival than rollers associated with other cavity types. Similarly, cavity type contributed weakly to explaining variation in recapture probability. It is possible that larger sample size could allow more sensitive analysis of the recapture data, but other factors appear to be currently relatively more important than the type of cavity. To our knowledge, the only study addressing the role of nest-site type on survival in birds is that by Libois et al. (2012) on Mediterranean Storm Petrels (Hydrobates pelagicus). These authors found higher survival rates of birds breeding in artificial nests than in natural sites and suggested that the former nest-site type offered greater protection against predators. In contrast to the Storm Petrel, that is under strong predation pressure from gulls, rollers in our study area do not suffer high predation rates (unpublished data), possibly accounting for the contrasting results.

Nest-box schemes can affect settlement patterns and apparent survival also indirectly through social effects, such as conspecific attraction (Muller et al. 1997, Hahn and Silverman 2006). Based on our previous findings, we predicted that social-ecological factors in terms of distances between breeding clusters and size of clusters could influence survival. Václav et al. (2011) found that roller nest re-occupancy was higher under high local conspecific breeding density. Because this variable combined both cluster size and distance to neighbors, we were not able to distinguish the underlying effect of breeding density and the indirect social effects of nest-box supplementation. We predicted that apparent survival should increase with decreasing distances between breeding clusters via conspecific social attraction effects owing to the positive effects of conspecific presence, but decrease with increasing size of breeding clusters because of increased intraspecific competition (see also Rodríguez-Ruiz et al. 2020). Our results based on the information-theory approach lend moderate support to the positive effect of smaller population fragmentation on apparent survival, suggesting the positive social effects not only on the probability of nest-site occupancy (Václav et al. 2011), but also on survival. Rollers might benefit from breeding and hatching in less fragmented populations, because attracting prospective mates could be faster and territory defense from predators or competitors could be more effective in such population clusters (Muller et al. 1997 and references therein). Interestingly, in contrast to adult rollers, juvenile males displayed higher apparent survival than juvenile females particularly under less fragmented natal populations. This result could again reflect the dominant role of male rollers in nest-site selection and their higher natal site fidelity compared with juvenile females. A differential effect of breeding density on survival within age classes has also been previously reported in Eurasian Spoonbills (Platalea leucorodia); a positive effect of density on annual survival was apparent in small populations for younger birds, whereas decreases in survival of younger birds were detected in increasing populations (Lok et al. 2013). Future work with more rigorous consideration of population indices is needed to clarify the mechanisms behind age-dependent survival.

\section{CONSERVATION CONCLUSIONS}

Our longitudinal study illustrates the flexibility in nest-site selection resulting in rapid colonization of a novel cavity type and population increase in a declining non-excavator cavity-nesting bird. Paradoxically, this species that evolved in heterogeneous breeding environments with ephemeral nesting sites is currently increasingly facing homogeneous nesting opportunities with persistent nest sites in stable or increasing nest-box populations across its European breeding range (Kiss et al. 2020). Evolutionary rescue via adaptive phenotypic plasticity has been suggested to facilitate conservation of declining species (Vander Wal et al. 2013), but environmental variation is indispensable for the evolution and maintenance of phenotypic plasticity (Bradshaw 1965, Stearns 1989, Van Buskirk 2012). The almost universal adherence to nest-box supplementation as the main conservation tool for species such as rollers can decrease the species' future responsiveness to environmental changes and turn it into a conservation-reliant species (Gameiro et al. 2020). That 
is to say, the higher natal and breeding fidelity of rollers associated with nest-boxes can cause rollers to select this cavity type even if the breeding habitat gradually becomes unsuitable (c.f. Robertson and Hutto 2006, Reynolds et al. 2019). Moreover, natal habitat preference induction can influence habitat preferences of adults (Davis and Stamps 2004). Importantly, even despite creating seemingly safer nesting opportunities (Valera et al. 2019), we did not find evidence for higher reproductive success (Valera et al. 2019) and higher apparent survival of rollers using nest-boxes and entrance-reduced nest sites compared with other nest substrates. Therefore, the results of this work further urge revisiting the largescale application of nest-box schemes and advocate for wider support of alternative nesting substrates, including natural ones (Valera et al. 2019).

The results of our long-term study suggest that declining nonexcavator cavity-nesting rollers can be particularly sensitive to population fragmentation, rather than to physical characteristics of their nesting substrates. Social information can profoundly influence the dynamics of populations (Gil et al. 2018) and both social information and conspecific attraction influence habitat selection in rollers (Václav et al. 2011). In the latter work, we suggested that conservation plans should consider reducing the effects of habitat fragmentation that could disrupt information webs also in solitary breeding species such as rollers (Holt 2007, Schmidt et al. 2010). This study corroborates the idea by showing that, unlike cavity type, conspecific breeding distribution in terms of distances between breeding clusters was associated with the apparent survival of rollers in the population with relatively high breeding densities. Stodola and Ward (2017) likewise demonstrated benefits of conspecific attraction in relatively stable environments. Yet, they also suggested that conspecific attraction, when coupled with site fidelity, may preclude a species from occupying new and potentially higher quality areas when habitat quality shifts rapidly. Our results demonstrate the empirical relevance of this claim and imply that measures that are intended to reverse the decline, particularly nest-box schemes, can make the populations even more vulnerable in the long-term via their indirect effects on site fidelity and conspecific attraction. Consequently, rather than as a broad-scale tool to support populations by provisioning with a superior nesting substrate, nest-box schemes could be applied at a fine scale to promote higher connectiveness of breeding populations. We endorse the view that conservation tools, including nest-box supplementation, need to be more seriously considered from the evolutionary perspective in future conservation management actions (Urlich 2015).

Responses to this article can be read online at: https://www.ace-eco.org/issues/responses.php/1928

\section{Acknowledgments:}

We thank Jesús Veiga, Miguel Ángel Calero-Torralbo, Maite Amat, Teresa Martinez, and Oliver Hoi for their help with fieldwork. Two anonymous referees contributed to improve the manuscript. Families Castillo-Zamora (Vellsam Materias Bioactivas), López
Segura-Escudero and Martínez-Escudero have kindly given their permission to work on their land. Junta de Andalucia kindly provided permits to sample birds and their nests. F. V. received financial support from the projects CGL2014-55969 and PGC2018-097426$B$-C22 ( MCIUIAEI/FEDER, UE). RV was funded by the Research Grant Agency (VEGA) of the Ministry of Education, Science, Research and Sport of the Slovak Republic and Slovak Academy of Sciences (2/0008/16 and 2/0023/20).

\section{LITERATURE CITED}

Barrientos, R., F. Valera, A. Barbosa, C. M. Carrillo, and E. Moreno. 2009. Plasticity of nest-site selection in the Trumpeter Finch: a comparison between two different habitats. Acta Oecologica 35:499-506. https://doi.org/10.1016/j.actao.2009.03.005

Bellrose, F. C., K. L. Johnson, and T. U. Meyers. 1964. Relative value of natural cavities and nesting houses for wood ducks. Journal of Wildlife Management 28:661-676. https://doi. org/10.2307/3798781

Berthier, K., F. Leippert, L. Fumagalli, and R. Arlettaz. 2012. Massive nest-box supplementation boosts fecundity, survival and even immigration without altering mating and reproductive behaviour in a rapidly recovered bird population. PLOS ONE 7: e36028. https://doi.org/10.1371/journal.pone.0036028

Beyer, G. L., and R. L. Goldingay. 2006. The value of nest boxes in the research and management of Australian hollow-using arboreal marsupials. Wildlife Research 33:161-174. https://doi. org/10.1071/WR04109

BirdLife International. 2004. Birds in Europe: population estimates, trends and conservation status. BirdLife International. Cambridge, UK.

BirdLife International. 2015. European red list of birds. Office for official publications of the European Communities, Luxembourg.

Bolton, M., R. Medeiros, B. Hothersall, and A. Campos. 2004. The use of artificial breeding chambers as a conservation measure for cavity-nesting procellariiform seabirds: a case study of the Madeiran Storm Petrel (Oceanodroma castro). Biological Conservation 116:73-80. https://doi.org/10.1016/S0006-3207(03) 00178-2

Bradshaw, A. D. 1965. Evolutionary significance of phenotypic plasticity in plants. Advances in Genetics 13:115-155. https://doi. org/10.1016/S0065-2660(08)60048-6

Brown, J. L., and M. W. Collopy. 2013. Immigration stabilizes a population of threatened cavity-nesting raptors despite possibility of nest box imprinting. Journal of Avian Biology 44:141-148. https://doi.org/10.1111/j.1600-048X.2012.05728.x

Burnham, K. P., and D. R. Anderson. 2002. Model selection and multimodel inference: a practical information-theoretic approach. Second edition. Springer-Verlag, New York, New York, USA

Burnham, K. P., D. R. Anderson, and K. P. Huyvaert. 2011. AIC model selection and multimodel inference in behavioral ecology: 
some background, observations, and comparisons. Behavioral Ecology and Sociobiology 65:23-35. https://doi.org/10.1007/ s00265-010-1029-6

Catry, T., and I. Catry. 2019. Nest-site provisioning re-shapes species interactions within bird assemblages. Ibis 161:699-704. https://doi.org/10.1111/ibi.12731

Choquet, R., J. D. Lebreton, O. Gimenez, A. M. Reboulet, and R. Pradel. 2009. U-CARE: Utilities for performing goodness of fit tests and manipulating CApture-REcapture data. Ecography 32:1071-1074. https://doi.org/10.1111/j.1600-0587.2009.05968.x

Clark, R. G., and D. Shutler. 1999. Avian habitat selection: pattern from process in nest-site use by ducks? Ecology 80:272-287. https://doi.org/10.1890/0012-9658(1999)080[0272:ahspfp]2.0.co;2

Cockle, K. L., K. Martin, and M. C. Drever. 2010. Supply of treeholes limits nest density of cavity-nesting birds in primary and logged subtropical Atlantic forest. Biological Conservation 143:2851-2857. https://doi.org/10.1016/j.biocon.2010.08.002

Collias, N. E., and E. C. Collias. 1984. Nest building and bird behavior. Princeton University Press, Princeton, New Jersey, USA. https://doi.org/10.1515/9781400853625

Cooch, E. G., and G. C. White. 2019. Program MARK. A gentle introduction. 19th version. [online] URL: http://www.phidot.org/ software/mark/docs/book/

Cramp, S. 1998. The complete birds of the Western Palearctic on CDROM. Oxford University Press, New York, New York, USA.

Danchin, E., T. Boulinier, and M. Massot. 1998. Conspecific reproductive success and breeding habitat selection: implications for the study of coloniality. Ecology 79:2415-2428. https://doi. org/10.1890/0012-9658(1998)079[2415:CRSABH]2.0.CO;2

Davis, J. M., and J. A. Stamps. 2004. The effect of natal experience on habitat preferences. Trends in Ecology and Evolution 19:411-416. https://doi.org/10.1016/j.tree.2004.04.006

Deeming, C. 2002. Avian incubation: behaviour, environment and evolution. Oxford University Press, Oxford, UK.

Deeming, D. C., and M. C. Mainwaring. 2015. Functional properties of nests. Pages 29-49 in D. C. Deeming and S. J. Reynolds, editors. Nests, eggs, and incubation: new ideas about avian reproduction. Oxford University Press, Oxford, UK. https:// doi.org/10.1093/acprof:oso/9780198718666.003.0004

Diamond, S. E., L. Chick, A. Perez, S. A. Strickler, and R. A. Martin. 2017. Rapid evolution of ant thermal tolerance across an urban-rural temperature cline. Biological Journal of the Linnean Society 121:248-257. https://doi.org/10.1093/biolinnean/blw047

Duckworth, R. A., K. K. Hallinger, N. Hall, and A. L. Potticry. 2017. Switch to a novel breeding resource influences coexistence of two passerine birds. Frontiers in Ecology and Evolution 5:72. https://doi.org/10.3389/fevo.2017.00072

Forstmeier, W., and I. Weiss. 2004. Adaptive plasticity in nest-site selection in response to changing predation risk. Oikos 104:487-499. https://doi.org/10.1111/j.0030-1299.1999.12698.x

Fox, R. J., J. M. Donelson, C. Schunter, T. Ravasi, and J. D. Gaitán-Espitia. 2019. Beyond buying time: the role of plasticity in phenotypic adaptation to rapid environmental change. Philosophical Transactions of the Royal Society B 374(1768). https://doi.org/10.1098/rstb.2018.0174

Fridolfsson, A. K., and H. Ellegren. 1999. A simple and universal method for molecular sexing of non-ratite birds. Journal of Avian Biology 30:116-121. https://doi.org/10.2307/3677252

Gameiro, J., A. M. A. Franco, T. Catry, J. M. Palmeirim, and I. Catry. 2020. Long-term persistence of conservation-reliant species: challenges and opportunities. Biological Conservation 243:108452. https://doi.org/10.1016/j.biocon.2020.108452

Geri, F., V. Amici, and D. Rocchini. 2010. Human activity impact on the heterogeneity of a Mediterranean landscape. Applied Geography 30:370-379. https://doi.org/10.1016/j.apgeog.2009.10.006

Gil, M. A., A. M. Hein, O. Spiegel, M. L. Baskett, and A. Sih. 2018. Social information links individual behaviour to population and community dynamics. Trends in Ecology and Evolution 33:535-548. https://doi.org/10.1016/j.tree.2018.04.010

Gimenez, O., J. D. Lebreton, R. Choquet, and R. Pradel. 2017. R2ucare: Goodness-of-fit tests for capture-recapture models. R package version 1.0.0. [online] URL: https://CRAN.R-project. org $/$ package $=$ R 2 ucare

Glutz von Blotzheim, U. N., and K. M. Bauer. 1980. Handbuch der Vögel Mitteleuropas, band 8. Akademische Verslagsgesellchaff, Wiesbaden, Germany.

Goldingay, R. L., and J. R. Stevens. 2009. Use of artificial tree hollows by Australian birds and bats. Wildlife Research 36:81-97. https://doi.org/10.1071/WR08064

Greenwood, P. J., and P. H. Harvey. 1982. The natal and breeding dispersal of birds. Annual Review of Ecology and Systematics 13:1-21. https://doi.org/10.1146/annurev.es.13.110182.000245

Hahn, B. A., and E. D. Silverman. 2006. Social cues facilitate habitat selection: American Redstarts establish breeding territories in response to song. Biology Letters 2(3). https://doi. org/10.1098/rsbl.2006.0472

Haramis, G. M., and D. Q. Thompson. 1985. Density-production characteristics of box-nesting Wood Ducks in a northern greentree impoundment. Journal of Wildlife Management 49:429-436. https://doi.org/10.2307/3801547

Holt, R. D. 2007. IJEE Soapbox: The unraveling of nature's information webs: the next depresing frontier in conservation? Israel Journal of Ecology and Evolution 53:229-236. https://doi. org/10.1560/ijee.53.3.229

Jones, R. E., and A. S. Leopold. 1967. Nesting interference in a dense population of Wood Ducks. Journal of Wildlife Management 31:221-228. https://doi.org/10.2307/3798310

Kirmse, V. W. 2001. Reintroduction of tree-nesting peregrines (Falco peregrinus) in central Europe. Zeitschrift für Jagdwissenschaft 47:165-177. https://doi.org/10.1007/bf02241547

Kiss, O., B. Tokody, K. Nagy, and Z. Végvári. 2020. Potential enlargement of the European Roller breeding range in the Carpathian Basin. Journal for Nature Conservation 56:125841. https://doi.org/10.1016/j.jnc.2020.125841 
Klein, A., T. Nagy, T. Csörgő, and R. Mátics. 2007. Exterior nestboxes may negatively affect Barn Owl Tyto alba survival: an ecological trap. Bird Conservation International 17:273-281. https://doi.org/10.1017/S0959270907000792

Kokko, H., and W. Sutherland. 2001. Ecological traps in changing environments: ecological and evolutionary consequences of a behaviourally mediated Allee effect. Evolutionary Ecology Research 3:537-551.

Laake, J. L. 2013. RMark: An R interface for analysis of capturerecapture data with MARK. AFSC Processed Rep 2013-01. Alaska Fisheries Science Center, NOAA, National Marine Fisheries. Service, Seattle, Washington, USA.

Lebreton, J. D., K. P. Burnham, J. Clobert, and D. R. Anderson. 1992. Modeling survival and testing biological hypotheses using marked animals: a unified approach with case studies. Ecological Monographs 62:67-118. https://doi.org/10.2307/2937171

Lessells, C. M., M. I. Avery, and J. R. Krebs. 1994. Nonrandom dispersal of kin: why do European bee-eater (Merops apiaster) brothers nest close together? Behavioral Ecology 5:105-113. https://doi.org/10.1093/beheco/5.1.105

Libois, E., O. Gimenez, D. Oro, E. Mínguez, R. Pradel, and A. Sanz-Aguilar. 2012. Nest boxes: a successful management tool for the conservation of an endangered seabird. Biological Conservation 155:39-43. https://doi.org/10.1016/j.biocon.2012.05.020

Lok, T., O. Overdijk, J. M. Tinbergen, and T. Piersma. 2013. Seasonal variation in density dependence in age-specific survival of a long-distance migrant. Ecology 94:2358-2369. https://doi. org/10.1890/12-1914.1

Lukacs, P. M., W. L. Thompson, W. L. Kendall, W. R. Gould, P. F. Doherty, K. P. Burnham, and D. R. Anderson. 2007. Concerns regarding a call for pluralism of information theory and hypothesis testing. Journal of Applied Ecology 44:456-460. https://doi.org/10.1111/j.1365-2664.2006.01267.x

Mainwaring, M. C. 2015. The use of man-made structures as nesting sites by birds: a review of the costs and benefits. Journal for Nature Conservation 25:17-22. https://doi.org/10.1016/j. jnc.2015.02.007

Mänd, R., V. Tilgar, A. Lõhmus, and A. Leivits. 2005. Providing nest boxes for hole nesting birds - does habitat matter? Biodiversity and Conservation 14:1823-1840. https://doi. org/10.1007/s10531-004-1039-7

Maness, T. J., and D. J. Anderson. 2013. Predictors of juvenile survival in birds. Ornithological Monographs 78:1-55. https://doi. org/10.1525/om.2013.78.1.1

Martin, T. E. 1993. Nest predation and nest sites: new perspectives on old patterns. Bioscience 43:523-532. https://doi.org/10.2307/1311947

Martin, T. E., and P. Li. 1992. Life history traits of open- vs. cavity-nesting birds. Ecology 73:579-592. https://doi.org/10.2307/1940764

McClure, C. J., B. P. Pauli, and J. A. Heath. 2017. Simulations reveal the power and peril of artificial breeding sites for monitoring and managing animals. Ecological Applications 27:1155-1166. https://doi.org/10.1002/eap.1509
Menzel, S. 2018. Artificial burrow use by burrowing owls in northern California. Journal of Raptor Research 52:167-177. https://doi.org/10.3356/JRR-17-05.1

Monti, F., L. Nelli, C. Catoni, and G. Dell'Omo. 2019. Nest box selection and reproduction of European Rollers in Central Italy: a 7-year study. Avian Research 10:13. https://doi.org/10.1186/ s40657-019-0150-0

Muller, K. L., J. A. Stamps, V. V. Krishnan, and N. H. Willits. 1997. The effects of conspecific attraction and habitat quality on habitat selection in territorial birds (Troglodytes aedon). American Naturalist 150:650-661. https://doi.org/10.1086/286087

Murtagh, F., and P. Legendre. 2014. Ward's hierarchical agglomerative clustering method: which algorithms implement Ward's criterion? Journal of Classification 31:274-295. https:// doi.org/10.1007/s00357-014-9161-z

Newton, I. 1998. Population limitation in birds. Academic, San Diego, California, USA.

Paradis, E., S. R. Baillie, W. J. Sutherland, and R. D. Gregory. 1998. Patterns of natal and breeding dispersal in birds. Journal of Animal Ecology 67:518-536. https://doi.org/10.1046/ j.1365-2656.1998.00215.x

Parejo, D., J. White, J. Clobert, A. Dreiss, and E. Danchin. 2007. Blue Tits use fledgling quantity and quality as public information in breeding site choice. Ecology 88:2373-2382. https://doi. org/10.1890/06-2000.1

Pärt, T. 1991. Philopatry pays: a comparison between Collared Flycatcher sisters. American Naturalist 138:790-796. https://doi. org/10.1086/285252

Patrick, S. C., and H. Weimerskirch. 2017. Reproductive success is driven by local site fidelity despite stronger specialisation by individuals for large-scale habitat preference. Journal of Animal Ecology 86:674-682. https://doi.org/10.1111/1365-2656.12636

Payevsky, V. A. 2016. Sex-biased survival and philopatry in birds: do they interact? Biology Bulletin 43:804-818. https://doi. org/10.1134/s1062359016080136

Pearce, J. M. 2007. Philopatry: a return to origins. Auk 124:1085-1087. https://doi.org/10.1093/auk/124.3.1085

Peluc, S. I., T. S. Sillett, J. T. Rotenberry, and C. K. Ghalambor. 2008. Adaptive phenotypic plasticity in an island songbird exposed to a novel predation risk. Behavioral Ecology 19:830-835. https://doi.org/10.1093/beheco/arn033

Pradel, R., J. E. Hines, J. D. Lebreton, and J. D. Nichols. 1997. Capture- recapture survival models taking account of transients. Biometrics 53:60-72. https://doi.org/10.2307/2533097

R Core Team. 2018. R: A language and environment for statistical computing. R Foundation for Statistical Computing, Vienna, Austria. [online] URL: https://www.R-project.org/

Rey, P. J. 2011. Preserving frugivorous birds in agro-ecosystems: lessons from Spanish olive orchards. Journal of Applied Ecology 48:228-237. https://doi.org/10.1111/j.1365-2664.2010.01902.x

Reynolds, S. J., J. D. Ibáñez-Álamo, P. Sumasgutner, and M. C. Mainwaring. 2019. Urbanisation and nest building in birds: a review of threats and opportunities. Journal of Ornithology 160:841-860. https://doi.org/10.1007/s10336-019-01657-8 
Richards, S. A. 2008. Dealing with overdispersed count data in applied ecology. Journal of Applied Ecology 45:218-227. https:// doi.org/10.1111/j.1365-2664.2007.01377.x

Richmond, S., E. Nol, and D. Burke. 2011. Avian nest success, mammalian nest predator abundance, and invertebrate prey availability in a fragmented landscape. Canadian Journal of Zoology 89:517-528. https://doi.org/10.1139/z11-017

Robertson, B. A., and R. L. Hutto. 2006. A framework for understanding ecological traps and an evaluation of existing evidence. Ecology 87:1075-1085. https://doi.org/10.1890/0012-9658 (2006)87[1075:AFFUET]2.0.CO;2

Rodríguez, J., J. M. Avilés, and D. Parejo. 2011. The value of nestboxes in the conservation of Eurasian Rollers Coracias garrulus in southern Spain. Ibis 153:735-745. https://doi. org/10.1111/j.1474-919X.2011.01161.X

Rodríguez-Ruiz, J., M. Expósito-Granados, J. M. Avilés, and D. Parejo. 2020. Apparent survival, growth rate and dispersal in a declining European Roller population. Journal of Ornithology 161:103-113. https://doi.org/10.1007/s10336-019-01699-y

Schlaepfer, M. A., M. C. Runge, and P. W. Sherman. 2002. Ecological and evolutionary traps. Trends in Ecology and Evolution 17:474-480. https://doi.org/10.1016/S0169-5347(02) 02580-6

Schleimer, A., C. Ramp, J. Delarue, A. Carpentier, M. Bérubé, P. J. Palsbøll, R. Sears, and P. S. Hammond. 2019. Decline in abundance and apparent survival rates of fin whales (Balaenoptera physalus) in the northern Gulf of St. Lawrence. Ecology and Evolution 9:4231-4244. https://doi.org/10.1002/ ece 3.5055

Schmidt, K. A. 2004. Site fidelity in temporally correlated environments enhances population persistence. Ecology Letters 7:176-184. https://doi.org/10.1111/j.1461-0248.2003.00565.x

Schmidt, K. A., S. R. X. Dall, and J. A. Van Gils. 2010. The ecology of information: an overview on the ecological significance of making informed decisions. Oikos 119:304-316. https://doi. org/10.1111/j.1600-0706.2009.17573.x

Slevin, M. C., A. E. Matthews, and T. J. Boves. 2018. Prothonotary Warbler demography and nest site selection in natural and artificial cavities in bottomland forests of Arkansas, USA. Avian Conservation and Ecology 13(2):5. https://doi.org/10.5751/ ACE-01235-130205

Stearns, S. C. 1989. The evolutionary significance of phenotypic plasticity. BioScience 39:436-445. https://doi.org/10.2307/1311135

Stodola, K. W., and M. P. Ward. 2017. The emergent properties of conspecific attraction can limit a species' ability to track environmental change. American Naturalist 189:726-733. https:// doi.org/10.1086/691469
Sutherland, D. R., P. Dann, and R. E. Jessop. 2014. Evaluation of artificial nest sites for long-term conservation of a burrownesting seabird. Journal of Wildlife Management 78:1415-1424. https://doi.org/10.1002/jwmg.783

Symonds, M. R., and A. Moussalli. 2011. A brief guide to model selection, multimodel inference and model averaging in behavioural ecology using Akaike's information criterion. Behavioral Ecology and Sociobiology 65:13-21. https://doi. org/10.1007/s00265-010-1037-6

Tokody, B., S. J. Butler, T. Finch, A. Folch, T. C. Schneider, T. Schwartz, F. Valera, and O. Kiss. 2017. The flyway action plan for the European Roller (Coracias garrulus). BirdLife International for the European Commission. Presented at the 12th Meeting of Conference of the Parties, Manila, Philippines. [online] URL: https://www.cms.int/sites/default/files/document/ cms_cop12_ap.12.4_e.pdf

Tucker, G. M., and M. F. Heath. 1994. Birds in Europe: their conservation status. BirdLife International (Conservation Series No. 3), Cambridge, UK.

Urlich, S. C. 2015. What's the end-game for biodiversity: is it time for conservation evolution? New Zealand Journal of Ecology 39:133-142.

Václav, R., F. Valera, and T. Martínez. 2011. Social information in nest colonisation and occupancy in a long-lived, solitary breeding bird. Oecologia 165:617-627. https://doi.org/10.1007/ s00442-010-1848-1

Valera, F., R. Václav, M. Á. Calero-Torralbo, T. Martínez, and J. Veiga. 2019. Natural cavity restoration as an alternative to nest box supplementation. Restoration Ecology 27:220-227. https:// doi.org/10.1111/rec.12841

Van Buskirk, J. 2012. Behavioural plasticity and environmental change. Pages 145-158 in U. Candolin and B. B. M. Wong, editors. Behavioural responses to a changing world: mechanisms and consequences. Oxford University Press, Oxford, UK. https://doi. org/10.1093/acprof:osob1/9780199602568.003.0011

Vander Wal, E., D. Garant, M. Festa-Bianchet, and F. Pelletier. 2013. Evolutionary rescue in vertebrates: evidence, applications and uncertainty. Philosophical Transactions of the Royal Society B 368:20120090. https://doi.org/10.1098/rstb.2012.0090

Villegas Vallejos, M. A., A. A. Padial, and J. R. S. Vitule. 2016. Human-induced landscape changes homogenize Atlantic forest bird assemblages through nested species loss. PLoS ONE 11: e0147058. https://doi.org/10.1371/journal.pone.0147058

White, C. M., N. J. Clum, T. J. Cade, and W. G. Hunt. 2002. Peregrine falcon (Falco peregrinus). The birds of North America. A. Poole, editor. Cornell Lab of Ornithology, Ithaca, New York, USA. https://doi.org/10.2173/tbna.660.p
Editor-in-Chief: Keith A.Hobson Subject Editor: Dave Shutler

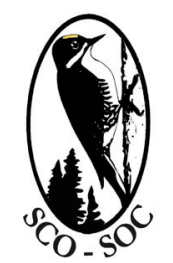

Sponsored by the Society of Canadian Ornithologists and Birds Canada

Parrainée par la Société des ornithologistes du Canada et Oiseaux Canada 